\title{
Scanning Electron Microscopy of the Electrochemical Corrosion Products of a Titanium Based Metallic Foam
}

\author{
L. Béjar ${ }^{*}$, E. Huape ${ }^{1}$, A. Medina ${ }^{1}$, Abraham A. Mejía $^{1}$, C. Aguilar ${ }^{2}$, I. Alfonso ${ }^{3}$. \\ 1. Facultad de Ingeniería Mecánica,Ingeniería Mecánica/Universidad Michoacana de San Nicolás de \\ Hidalgo, Edificio “J”, Ciudad Universitaria. Morelia, Michoacán México C.P. 58000. \\ 2. Departamento de Ingeniería Metalúrgica y Materiales/Universidad Técnica Federico Santa María, Av. \\ España 1680, Valparaíso, Chile. \\ 3. Instituto de Investigaciones en Materiles, Departamento de Materiales/UNAM Campus Morelia, \\ Antigua carretera a Pátzcuaro 8701, Morelia, Mich., México. 58190. \\ * Corresponding author: lbejargomez@yahoo.com.mx
}

The Electrochemical analysis is one of the methods used in metal alloys with biomedical applications using synthetic saliva, mouth rinse, Hank's solution, sodium silicate as a means, to mention a few [1]. The main objective of this work is to observe the results obtained from the metallic foam of $75 \%$ Ti-13\% Ta12\% Sn with 30\% spacer by the electrochemical method of potentiodynamic polarization curves using synthetic saliva at $37^{\circ} \mathrm{C}$ and a $\mathrm{pH}$ of 6.8 . The electrochemical test was carried out in a three-electrode cell arrangement, Saturated Calomel reference electrode (SCE), graphite auxiliary electrode (AE) and the working electrode (WE), the potential was varied in a range of $-1500 \mathrm{mV}$ to $+1500 \mathrm{mV}$ with respect to the open circuit potential (OCP) [2]. The working electrode was the foam with $30 \%$ of the spacer, which was obtained from a mechanical mixture of $75 \%$ Ti-13\% Ta-12\% Sn powders in \% by weight. Pouring them into a matrix of $8 \mathrm{~mm}$ in diameter, they were compacted at $430 \mathrm{MPa}$. To obtain the green with a length of $8 \mathrm{~mm}$, later they were sintered in a conventional oven at $1200{ }^{\circ} \mathrm{C}$ in an argon atmosphere. Scanning electron microscopy (SEM) + EDS was performed. In figure 1, the potentiodynamic curve is observed, in which an active dissolution behavior can be observed throughout the test. The electrochemical results have a corrosion potential $\left(\mathrm{E}_{\text {corr }}\right)$ of $-451 \mathrm{mV}$. The obtained Tafel slopes were, anodic beta $(\beta \mathrm{a}) 120$ $\mathrm{mV} /$ decade and as cathodic beta $(\beta \mathrm{c}) 158 \mathrm{mV} /$ decade. While the value of the corrosion current density ( $\mathrm{i}_{\text {corr }}$ ) was $0.00149 \mathrm{~mA} / \mathrm{cm}^{2}$. On the other hand, Figure 2 shows the images of SEM, where it is possible to appreciate corrosion products on the surface, in the same way, small cracks are perceived. The semiquantitative EDS analysis of the electrochemical test in the synthetic saliva at $37{ }^{\circ} \mathrm{C}$ showed high concentrations of Tantalum and Carbon. by literature indicates that $\mathrm{Ta}$ and $\mathrm{O}$ with high concentration may be a sublayer of $\mathrm{TaO}_{2}$ formed as a corrosion product [3]. In the case of carbon it is observed that the residues could be considered by the element used as a spacer $\left(\mathrm{NH}_{4}\right)_{2} \mathrm{CO}_{3}$. The other elements of the alloy such as Tin and Titanium were not considerable. The presence of oxygen could be attributed to the formation of an oxide.

\section{References:}

[1] A. Mariano, R. G. Oliveira, M. A. Fernandes, and E. C. S. Rigo, Revista Materia, volume 14 (2009), p.878-880.

[2] M. M. Machado-López, J. Faure, M. A. Espinosa-Medina, M. I. Espitia-Cabrera, and M. E. ContrerasGarcía, Electrochemical Society, volume 162 (2015), p.D3090-D3100.

[3] N. Montañez, D. Peña, and H. Estupiñan, Investigación, Optimización y Nuevos porcesos de Ingeniería, volume 21 (2008), p.87-96. 


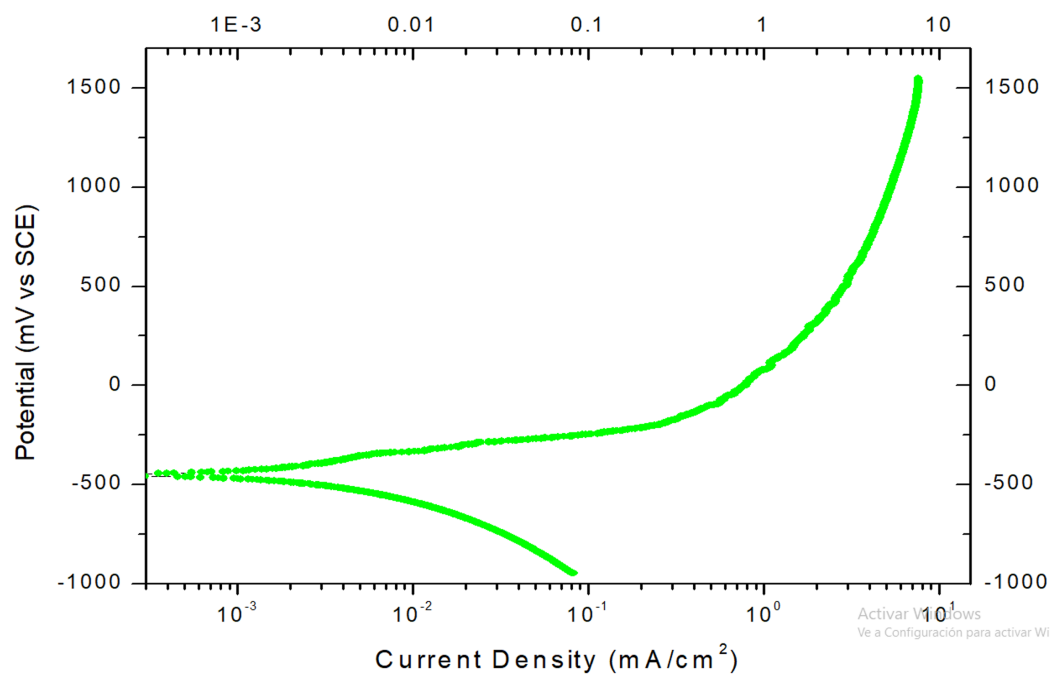

Figure 1. Potentiodynamic polarization plot of Metallic Foam Titanium Base
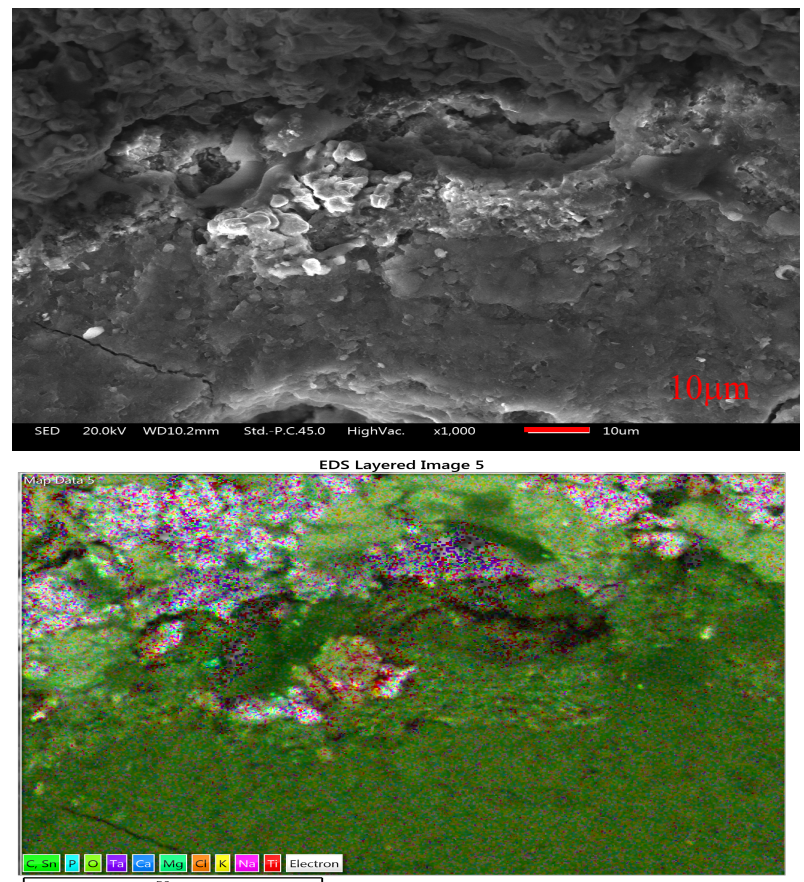

Ti $K \alpha 1$

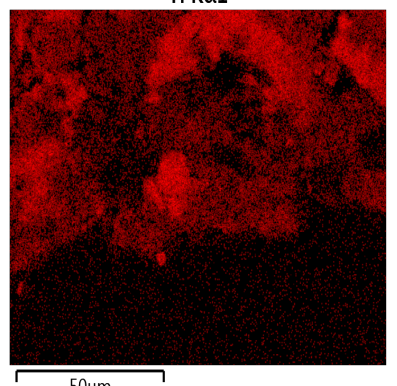

$50 \mu \mathrm{m}$

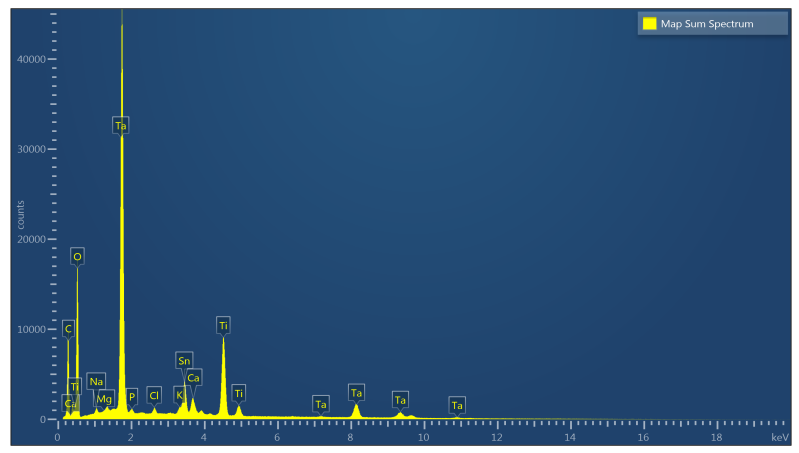

C Ka1_2

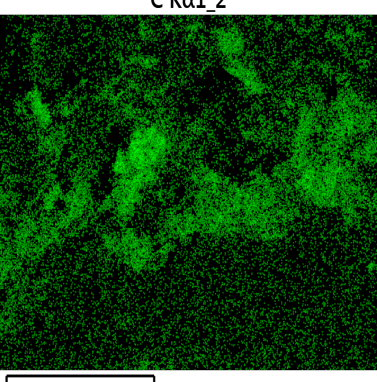

$50 \mu \mathrm{m}$
$\mathrm{OK \alpha 1}$

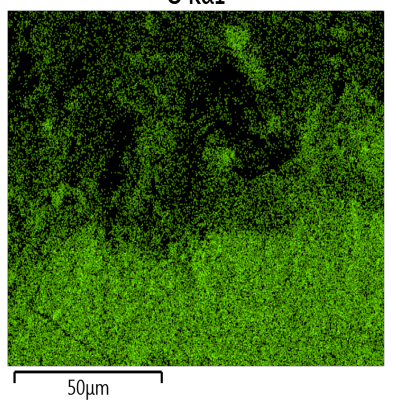

Sn L $\alpha 1$

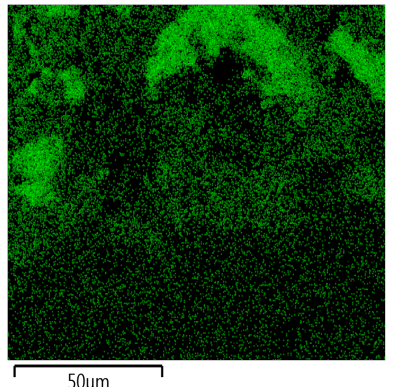

Ta L $\alpha 1$

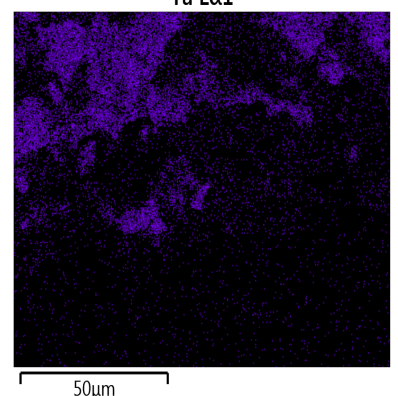

$50 \mu \mathrm{m}$

Figure 2. Photomicrographs SEM and X-ray mappings EDS of Titanium based Metallic Foam, corroded in synthetic saliva at $37^{\circ} \mathrm{C}$. 